\title{
Movement, home range size and activity pattern of the golden jackal (Canis aureus, Linneaus, 1758) in Huai Kha Khaeng Wildlife Sanctuary, Thailand
}

\author{
KHWANRUTAI CHARASPET ${ }^{1}$, RONGLARP SUKMASUANG ${ }^{1, \bullet}$, NORASET KHOEWSREE ${ }^{1}$, \\ MANANYA PLA-ARD ${ }^{1}$, NUCHARIN SONGSASEN ${ }^{2}$, SAKSIT SIMCHAREON ${ }^{3}$ \\ ${ }^{1}$ Department of Forest Biology, Faculty of Forestry, Kasetsart University, Chatuchak District, Bangkok 10900, Thailand. `email: mronglarp@ gmail.com. \\ ${ }^{2}$ Smithsonian's National Zoo \& Conservation Biology Institute. 3001 Connecticut Ave., NW Washington, DC 20008 \\ ${ }^{3}$ Wildlife Research Group, Department of National Parks Wildlife and Plant Conservation. Chatuchak District, Bangkok, Thailand 10900
}

Manuscript received: 23 September 2019. Revision accepted: 30 November 2019.

\begin{abstract}
Charaspet K, Sukmasuang R, Khoewsree N, Pla-ard M, Songsaen N, Simchareon S. 2019. Movement, home range size and activity pattern of the golden jackal (Canis aureus, Linneaus, 1758) in Huai Kha Khaeng Wildlife Sanctuary, Thailand. Biodiversitas 20: 3430-3438. We studied the movement patterns, monthly home range sizes, and activity patterns of the golden jackal in Huai Kha Khaeng Wildlife Sanctuary (HKK) from November 2017 to June 2019. Data were obtained by trapping and collaring a female jackal with a satellite collar, and from a concurrent camera trap survey. The female jackal had an average daily movement of $1.7 \mathrm{~km}$, and her overall home range size was $26.3 \mathrm{~km}^{2}$, based on 1,191 locations across 7 months and using the 95\% Minimum Convex Polygon (MCP) method. The monthly home range size $(95 \% \mathrm{MCP})$ was the smallest in December $\left(9.2 \mathrm{~km}^{2}\right)$ and the largest in March $(20.51 \mathrm{~km})$. Results from camera traps revealed 33 species of wild animals, including 16 species of carnivorous mammals and 17 non-carnivorous species. The relative abundance index (RAI) of the jackal was 24.33 , which was the highest of all carnivore species, and the secondhighest of all species, suggesting jackals were one of the most common mammal species in HKK. Based on camera trap data, the mean diel activity of jackals in HKKwas at 00: 46 hours, and their activity overlapped most with potential prey including hares and small rodents. Results also revealed that golden jackals prefer dry dipterocarp forest compared to other habitat types Our results lead to a better understanding of the ecology of golden jackals in Thailand, and provide a baseline for future research on this species.
\end{abstract}

Keywords: Abundance, carnivorous mammal, home range, time overlap, satellite collar

\section{INTRODUCTION}

The golden jackal (Canis aureus, Linneaus 1758) is a medium-sized canid with the largest distribution of any jackal species (Sheldon 1992). They range from central Europe across the Arabian Peninsula, Indian Peninsula, Sri Lanka, and Southeast Asian countries to Vietnam (Sheldon 1992; Jhala and Moehlman 2004). Genetically, golden jackals are most closely related to the Ethiopian wolf $(C$. simiensis), followed by the coyote (C. latrans), African golden wolf (Canis anthus), Himalayan wolf (C. l. chanco), peninsular Indian wolf $(C$. l. pallipes) and Grey wolf $(C$. lupus) (Yumnam et al. 2015). They are adapted to living in nearly all kinds of environments, including desserts, grassland, various types of forests (e.g. dry dipterocarp, mixed deciduous), agriculture land and human settlements (MacDonald 1979; 1984; Roberts 1997; Giannatos et al. 2010; Hunter and Barrett 2011). They are found in areas as high as 3,800 meters above sea level in Ethiopia (SilleroZubiri et al. 1996). Š́lek et al. (2014) studied the golden jackal population in the Balkan Peninsula covering 4 countries, including Bulgaria, Serbia, Croatia, and Romania, and found 266 families or territorial groups of golden jackal in a study area of 4,296 km2, or equivalent to 0.6 families or territorial groups per $10 \mathrm{~km}^{2}$. Aiyadurai and Jhala (2006) conducted a home range study on golden jackal using radio-collars for 13 months in Velavadar National Park, India and found that the home range was 29.77 (SE 10.99) $\mathrm{km}^{2}$ when calculating with the $95 \%$ Adaptive Kernel home ranges method and 14.30 (SE 4.06) $\mathrm{km}^{2}$ when calculating with the $95 \%$ Minimum Convex Polygon (MCP). Rotem et al. (2008) studied the effect of human activities on the home range of golden jackal in Israel and found that the jackals in natural areas had a home range of $21.2 \pm 9.3 \mathrm{~km}^{2}$, whereas the home range of the jackals near human-dominated areas was $6.6 \pm 4.5 \mathrm{~km}^{2}$. Simchareon (1998) reported the home range of a radiocollared male jackal monitored for 16 months in Huai Kha Khaeng Wildlife Sanctuary (HKK) to be $9.23 \mathrm{~km}^{2}$, while Hunter and Barrett (2011) reported the territory of golden jackals to be $1.1-20 \mathrm{~km}^{2}$. Golden jackals prey mostly on small animals e.g. hares, small rodents, ground birds or ungulate calves (Schaller 1972; Kingdon 1977). They are also scavengers, eating animal carcasses and also human trash (Schaller 1972; Poche et al. 1987). Aiyadurai and Jhala (2006) analyzed 150 scats of golden jackals and found that blackbuck (Antilope cervicapra) (33\%) and domestic cattle $(32 \%)$ were the main prey species. They also reported that the jackals travel $6.8 \mathrm{~km}$ (SE 1.05; range 0.4-12.1) at night to find food and that they forage near human settlement, feeding on livestock carcasses and trash in areas around human communities bordering the forest. 
Even though golden jackals are classified as carnivores, they can also eat wild fruit, seeds, roots (Lanszki and Szabó 2006; Lanszki et al. 2009), insects, birds, amphibians and reptiles (Mukherjee et al. 2004; Giannatos et al. 2010; Ćirović 2014). Mahmood and Nadeem (2013) studied the content in golden jackal scats in Pakistan, and found 27 different types of food, the largest quantity being animals (46.47\%), followed by grasses $(25.08 \%)$, soil $(22.42 \%)$ and insects $(5.35 \%)$. The prey species found were rodents, mongoose, squirrel, bamboo rat, birds as well as livestock including poultry, cattle, goat, sheep and domestic dogs. There were also reports of jackals scavenging wild boar carcasses and livestock carcasses as well (Yom-Tov et al. 1995).

Simchareon (1998) studied habitat use of golden jackal in HKK using radio collars, and found that the jackals spent most of their time in dipterocarp forest. Reports show that jackals will rest in ground burrows, small caves, hollows in trees and logs or in grasslands during the day (Prater 1971; Lekagul and McNeely 1988). Mukherjee et al. (2018) studied the selection of suitable ground burrows for jackals to rear their pups in India, and found that burrow selection was based on the amount of perennial plants and undergrowth, whereas open areas had a negative effect. The HKK in the western part of Thailand was declared as a World Nature Heritage Site and is an important natural habitat for golden jackals. Studies on the home range and movements using satellite collars have not occurred before in HKK. Similarly, data on the activity and relative abundance of jackals in HKK is lacking. The objective of this study is to understand the movement, home range, relative abundance and temporal overlap of jackals and other species in HKK and compare these results with other areas, including Khao Yai National Park and Khao Ang Rue Nai Wildlife Sanctuary, to improve the understanding of the spatial and temporal relations of jackals in Thailand. The results will increase our understanding of jackal ecology in Thailand, and provide important baseline information for future studies.

\section{MATERIALS AND METHODS}

\section{Study area}

The study was conducted in Nang Ram Valley in HKK, between Khao Nang Ram Research Station and the HKK head office, which covers an area of about $200 \mathrm{~km}^{2}$ (Figures 1). Nang Ram Valley is within the borders of Huai Thap Salao (Thap Salao stream). The flora in the area is mainly dipterocarp forest, mixed deciduous and dry evergreen forest in the moist areas along the stream. This area has forest fires every year. Some areas, especially near the banks of Huai Thap Salao, were once human settlements, but people had been relocated. There are many forest roads leading to this area. Many important threatened fauna are found in this area such as sambar deer, tiger, leopard, dhole, banteng, and elephants (Forest Research Center 1997(. Records collected for 30 years, from 1981 to 2010, show that HKK has an average annual temperature of $26-28^{\circ} \mathrm{C}$, with the average maximum temperature of $32-34$
${ }^{\circ} \mathrm{C}$ in April and May and the average minimum temperature of $20-24^{\circ} \mathrm{C}$. The average annual precipitation is approximately $1,100-1,200 \mathrm{~mm}$, with $105-110$ days of rainfall annually. The month with the highest rainfall is September, with precipitation of 220-240 mm (Thai Meteorological Department 2019.

\section{Procedures}

\section{Data collection}

Jackal trapping was performed using soft catch traps placed in the study area. Five-eight trap stations were settled in the area during August and November. To capture the jackal we used Onedia Victor \#1 $1 \frac{1}{2}$ soft catch leg-hold traps (Minnesota Trapline Products, Pennock, MN, USA). Each trap station composed of 9-11 leg-hold trap sets. The trap sites were baited with cattle meat and a motion-triggered VHF transmitter was placed at each trap site to detect when animals had sprung the trap. The signals from the transmitters were monitored every 15 minutes for 24 hours/day throughout the trapping period to ensure the highest safety for the captured animals. Camera traps were also placed at the site to check the species of animals entering the trap and eating the bait. A female jackal was successfully trapped on 20 November 2018 and a LOTEX Litetrack iridium 360 satellite collar (Lotek Wireless INC. 2019), weighing $500 \mathrm{~g}$, was deployed on the animal. After fitting the collar, the jackal was released at the capture site. The collar was set to send a signal every 4 hours to report the date, time and GPS location, and data were downloaded from the Sirtrack website. Although we programmed the satellite signal to be sent every 4 hours, in order to obtain a large amount of parametric data and be independent, there were times when the signal could not be sent. The collar also transmitted a VHF signal to help track the animal in the field with telemetry antennas.

Twenty Bushnell Trophy Cam HD Essential E2 12MP Trail Camera sets were used. A camera trap study was performed by dividing the 1: 50,000 geographic map into 1 $\mathrm{km}^{2}$ grid cells, and placing a camera within each grid (Gupta et al. 2009; Jenks et al. 2011; Siripattaranukul et al. 2015a,b). Cameras were deployed in 15-20 grids per field trip. The cameras were placed more than $500 \mathrm{~m}$ apart for the independence of photography in each grid, reducing the probability of photographing the same animal with different cameras (Jenks et al. 2012). The selection of the deployment location was chosen from the suitability of each area e.g. animal trails and tracks (Prayoon et al. 2012; Lynam et al. 2013; Wongchoo et al. 2013; Siripattaranukul et al. 2015a,b).

Camera traps were placed $30-40 \mathrm{~cm}$ above the ground and 3-4 $\mathrm{m}$ from the target point (Chutipong et al. 2014) or according to the suitability of the area. The cameras were set to take 3 consecutive photographs, 10 seconds apart, once triggered and were set to run 24 hours (Network 2008) for 30 days. After 30 days, the cameras were moved to new locations. The GPS locations of each camera station were recorded. The camera trap survey was performed from November 2017 to October 2018 within Nang Ram Valley, 95 camera trap locations and 2,260 trap nights were performed. 


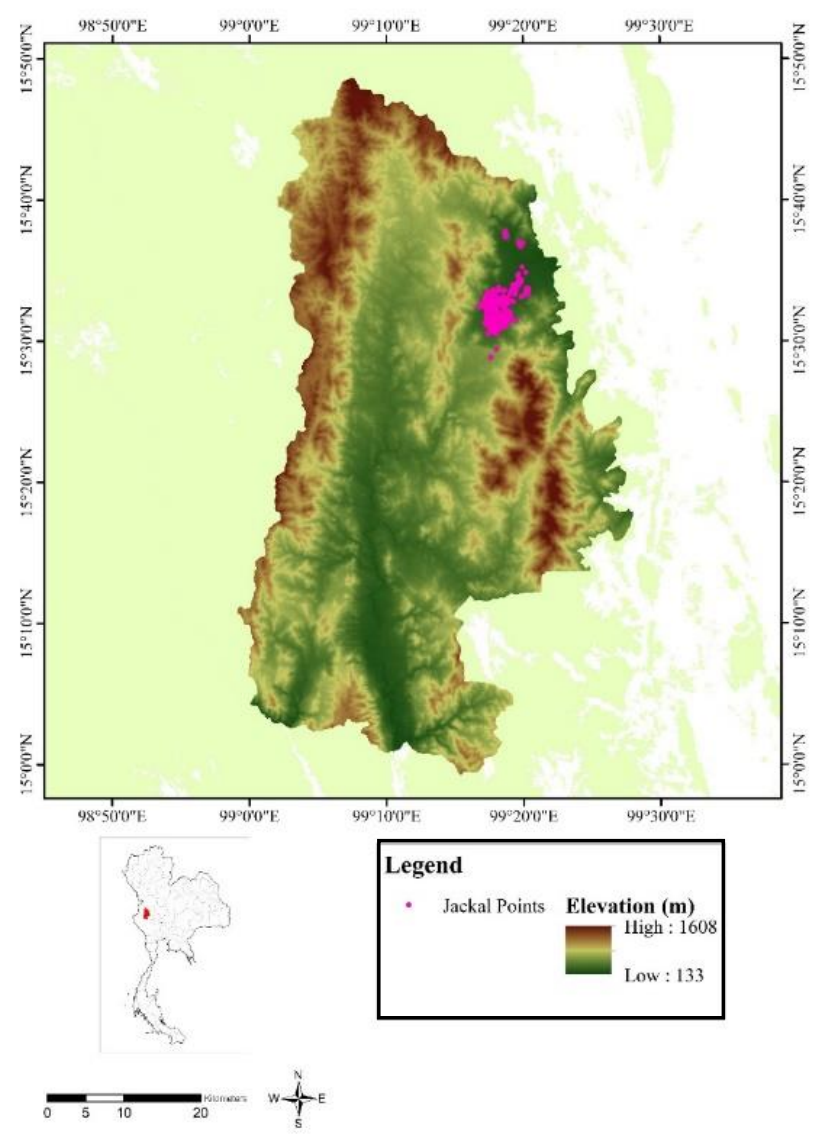

Figure 1. Huai Kha Khaeng Wildlife Sanctuary and the study area, Nang Ram Valley, Thailand. The pink locations represent the GPS locations of the adult female golden jackal.

All photographs were imported to the computer and organized with the Camera Trap Manager program (Zaragozi et al. 2015). The data was then transferred to Microsoft Excel for data analysis.

\section{Data analysis}

The satellite data obtained from the Sirtrack-Lotex website that included the ID of the animal, geographic location, date and time received was arranged. The data was processed in format and then travel distance, including the median, mean, leave-one-out error and maximum speed per hour, were calculated using OpenJump Program (Steiniger and Hunter 2013). The home range was also calculated at $95 \%, 75 \%$, and $50 \%$ using the minimum convex polygon (MCP) method (Mohr 1947; Worton 1989; White and Garrot 1990; Aiyadurai and Jhala 2006), with the OpenJump program (Steiniger and Hunter 2013). and the Autocorrelated Kernel Density Estimation (AKDE) method using ctmm package (Calabrese and Fleming 2016) in R (The R Core Team 2017) was also used to calculate the size of home range. The BIOTA program (Ecological Software Solutions 2019) was used to test the jackal's direction of movement $\left(\mathrm{H}_{0}\right.$ : movement direction is random)

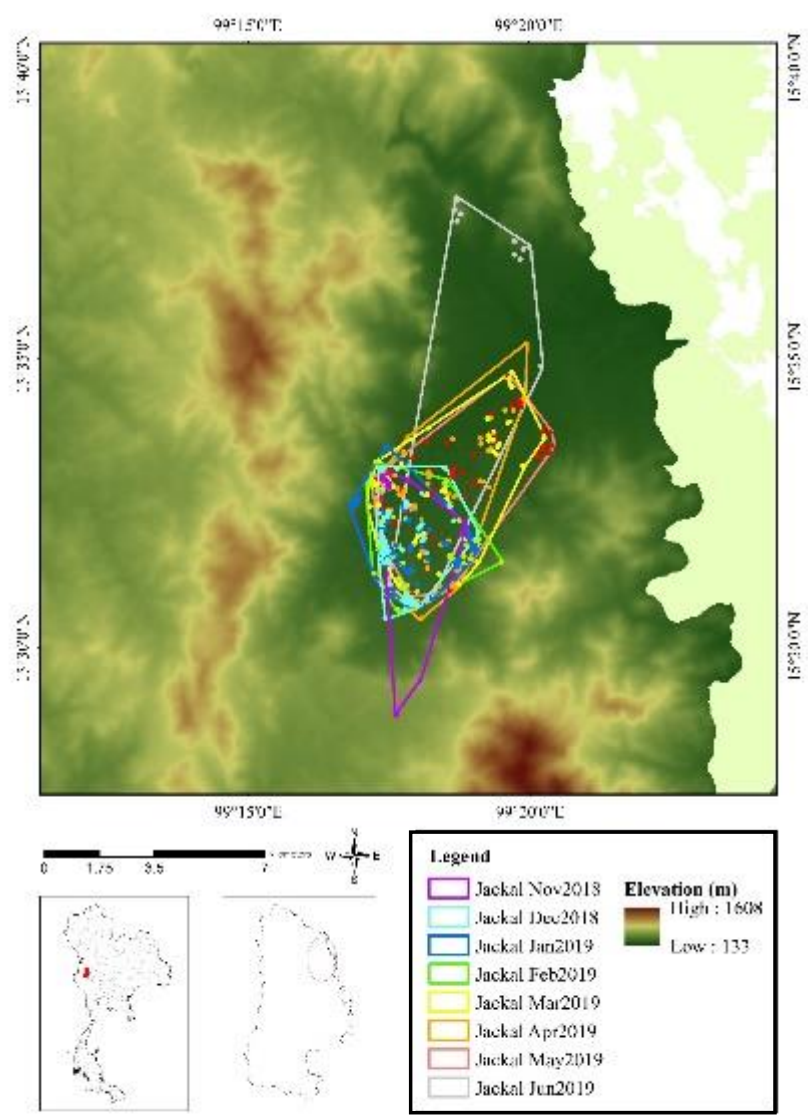

Figure 2. The study area 'Nang Ram Valley' in Huai Kha Khaeng Wildlife Sanctuary, Thailand, with the locations and home ranges of the jackal monitored with the satellite collar in each month from November 2018 to June 2019

with Roa's spacing test method (Batschelet 1981) at the significance level of 0.05 . To determine forest habitat selection, the forest categories, dry dipterocarp forest, mixed deciduous forest and also dry evergreen forest if present, within the $100 \%$ MCP home range area was classified. Number of GPS locations that fall in each forest habitat was counted and then Chi-square test was used to compare between observed and expected to determine forest habitat used. The significant difference was determined at $\mathrm{P}<0.05$.

The carnivorous species in the camera trap photographs were identified using the common name and scientific name according to Lekagul and McNeely (1988). Only the photographs that could be clearly identified with the date and time recorded on the photograph were used. Photographs with more than one carnivorous species within the same photo were counted as one incidence for each species (Jenks et al. 2011). The criterion for independence of animal photographs was (i) consecutive photographs of different animals of either the same or different species, (ii) consecutive photographs of the same animal, same species which were > 30 minutes apart, (iii) nonconsecutive 
photographs of the same animal of the same species (O'Brien et al. 2003).

The activity pattern data recorded from the camera traps were summarized by compiling the data and classifying by species, dividing the time period into 06: 01-17: $59 \mathrm{hrs}$ as day time and 18: 00-06: $00 \mathrm{hrs}$ as nighttime (Azlan and Sharma 2006; Azlan 2009). The analyzed data was made into activity graphs of the carnivores and other prey species. The activity pattern of the jackal was studied from the time on the photographs, and analyzed with ORIANA version 4.02 (Kovach Computing Services 2019). The Mean Vector: $\mu, 95 \%$ Confidence Interval for $\mu$ and Circular Variance were calculated. Comparison of the presence of the jackals in different time periods between each area was done with Watson's U tests. The average difference between the time of presence of the jackals in each area from the camera traps was considered significant when $\mathrm{P}<0.05$.

When calculating the \%Relative abundance (\%RAI) of each species, the species were divided into carnivorous mammals and non-carnivorous species. The calculation used the formula RAI $=\mathrm{N}(100) / \mathrm{A}$. Where $\mathrm{N}$ is the Number of independent photographs and $\mathrm{A}$ is the total trap days.

The pattern of temporal overlap between jackals and other species was calculated by a method developed by Ridout and Linkie (2009), who used the Kernel density estimation method using the overlap package (Meredith and Ridout 2018) in R (Fernandez-Duran 2004; The R Core Team 2017) to measure the degree of temporal overlap of 2 species of animals, which is called the oefficient of overlap $(\Delta)$. This means the area under the graph or curve that shows the time that both species are present by taking the minimum of the density function of the 2 compared species at each location. Thus $\Delta=1$ means that there is an overlap of the activities, whereas $\Delta=0$ means there is no overlap of the activities. The confidence level of the coefficient of overlap was calculated by 500 bootstraps (Linkie and Ridout 2011).

\section{RESULTS AND DISCUSSION}

\section{Movement pattern}

Satellite data from the female jackal was received from 20 November 2018 to 26 June 2019, which totaled 218 days and 1,191 locations. The median of the movement distance for each month ranged from shortest distance of $0.6 .5 \mathrm{~km}$ in December 2018 to the longest distance of $3.1 \mathrm{~km}$ in April 2019. The Leave-one-out error of the median in each month is shown in Table 1 . The mean movement distance per day ranged from a low of $1.4 \mathrm{~km}$ in June 2019 to a high of $3.1 \mathrm{~km}$ in April 2019. The overall mean average monthly movement distance per day was $2.2 \mathrm{~km}$.

The maximum movement speed of the jackal was between 1.04 and $3.74 \mathrm{~km} /$ hour. The month with the fastest movement speed was November, which was $3.74 \mathrm{~km} /$ hour and the slowest in December 2019 at $1.04 \mathrm{~km} / \mathrm{hour}$. The overall median travel distance per day was $5.4 \mathrm{~km}$, the overall mean distance traveled per day was $5.9 \mathrm{~km}$ and the overall mean speed of travel was $3.74 \mathrm{~km} /$ hour as shown in Table 1.

The daily movements of golden jackals have only been reported in one previous study by Patil and Jhala (2008). They reported the movement of an adult male jackal in Bhal region of Gujarat, India, tracked with a VHR radio collar. That jackal's activity started at 19: $22 \mathrm{hrs}$ and on average, it went back to its resting site at 7: $00 \mathrm{hrs}$. The average movement distance per night was $8.58 \mathrm{~km}(\mathrm{SE}=2.46, \mathrm{n}=$ $6)$. The distance traveled was $0.74 \mathrm{~m} / \mathrm{hr}(\mathrm{SE}=0.20, \mathrm{n}=69$ hours), and the movement distance per day was $9.55 \mathrm{~km}$.

\section{Movement direction}

When testing the movement direction using Roa's spacing test, the main hypothesis $\left(\mathrm{H}_{0}\right)$ was stated as the jackal moves randomly (Table 2). Results from monthly tests show that only in January did the jackal not move randomly but with significant specific directions, which was possibly due to reproductive behavior. That period was winter during which jackals were seen to hunt in pairs more than alone, sometimes with up to 3-4 animals, and this is when pairing occurs for mating and building a den for the pups. Giannatos (2004) reported that jackals pair up in January and February. The female has a gestation period of 63 days and gives birth to 2-4 puppies in ground burrows, rock caves or tree hollows. The female will rear the young for 8 weeks (Hoffmann et al. 2018). In the other months, the monthly movement and total movement characteristics were significantly random.

When analyzed with 95\% Autocorrelated Kernel Density Estimation (AKDE), the largest monthly home range was in March (38.95 $\mathrm{km}^{2}$ ) (Table 3), which indicates the non-random movement direction was also related to monthly home range size. This is in accordance with Simchareon (1998), who reported that the activity radius and the movement distance between the center of the home range of a male jackal tracked with VHF collar in HKK were highest in January.

\section{Home range size}

The jackal's home range across all months was 26.30 $\mathrm{km}^{2}$ (95\% MCP) and $34.82 \mathrm{~km}^{2}$ (95\% AKDE; Table 3). The size of monthly home ranges varied, which the smallest in December $\left(9.2 \mathrm{~km}^{2} ; 95 \% \mathrm{MCP}\right)$ and largest in March (20.51 km²; 95\% MCP; Table 3; Figure 1). The home range in this study was similar to the home range of the male jackal studied by Aiyadurai and Jhala (2006) in Velavadar National Park, India, which was monitored with a radio collar for 13 months and found to have a home range of $29.77 \mathrm{~km}^{2}$ (95\% Adaptive Kernel) and $14.30 \mathrm{~km}^{2}$ (95\% MCP). In case AKDE based on this study, it also showed semivariance of home range and time lag (day and month) (Figure 3). The monthly home range analysis omitted in November and June due to small number of locations received (19 and 47 locations respectively). However, the total number of locations was analyzed in the overall data. 
Table 1. Movement characteristics of an adult female Asiatic jackal monitored with a GPS collar in Huai Kha Khaeng Wildlife Sanctuary, Thailand from November 2018 to June 2019

\begin{tabular}{|c|c|c|c|c|c|c|}
\hline \multirow[b]{2}{*}{ Month } & \multirow[b]{2}{*}{$\mathbf{N}$} & \multicolumn{4}{|c|}{ Distance/Day } & \multirow[b]{2}{*}{$\begin{array}{c}\text { Max speed }(\mathbf{K m} / \mathbf{h}) \\
(V) M\end{array}$} \\
\hline & & Median & $\begin{array}{l}\text { Leave-one-out } \\
\text { error median }\end{array}$ & Mean & $\begin{array}{l}\text { Leave-one-out } \\
\text { error mean }\end{array}$ & \\
\hline Nov 2018 & 27 & 705.14 & 21.71 & $2,877.42$ & 162.58 & 3.74 \\
\hline Dec 2018 & 197 & 653.39 & 26.16 & $1,487.21$ & 93.29 & 1.04 \\
\hline Jan 2019 & 228 & $1,471.24$ & 23.20 & $1,505.56$ & 109.60 & 1.29 \\
\hline Feb 2019 & 202 & $2,231.88$ & 26.36 & $1,943.76$ & 148.84 & 1.21 \\
\hline Mar 2019 & 120 & $2,669.02$ & 41.48 & $2,730.93$ & 258.32 & 1.28 \\
\hline Apr 2019 & 226 & $3,122.66$ & 36.35 & $3,138.11$ & 269.34 & 1.77 \\
\hline May 2019 & 144 & $2,411.48$ & 41.78 & $2,572.65$ & 276.43 & 1.95 \\
\hline Jun 2019 & 47 & 705.11 & 27.31 & $1,383.50$ & 100.79 & 1.16 \\
\hline Pooled data (Nov-Jun 2019) & 1191 & $5,350.37$ & 28.84 & $5,896.01$ & 180.37 & 3.74 \\
\hline Monthly average & 148.87 & 1.74 & 30.54 & 2.20 & 177.39 & 1.68 \\
\hline SE (monthly) & 27.85 & 0.35 & 2.86 & 0.24 & 27.83 & 0.31 \\
\hline
\end{tabular}

Table 2. Movement direction of the adult female jackal monitored with a GPS collar, divided by month and pooled data from 20 November 2018 to 26 June 2019 in Huai Kha Khaeng Wildlife Sanctuary, Thailand

\begin{tabular}{lccc}
\hline \multicolumn{1}{c}{ Month } & Angle count (N) & $\begin{array}{c}\text { Roa's spacing test } \\
\text { Result statistic (U) }\end{array}$ & P value \\
\hline Nov 2018 & 19 & 118.06 & 0.68 \\
Dec 2018 & 194 & 160.72 & 1.00 \\
Jan 2019 & 224 & $146.48 *$ & 0.02 \\
Feb 2019 & 203 & 161.21 & 1.00 \\
Mar 2019 & 118 & 130.67 & 0.55 \\
Apr 2019 & 224 & 136.31 & 0.26 \\
May 2019 & 142 & 127.25 & 0.71 \\
Jun 2019 & 47 & 126.39 & 0.62 \\
Pooled data (Nov-Jun 2019) & 1,184 & 154.24 & 1.00 \\
\hline
\end{tabular}

Notes: $\mathrm{H}_{0}$ : was stated as the jackal moves randomly. $\mathrm{H}_{\mathrm{A}}$ : was stated as the jackal did not move randomly. *: Significant difference at $\mathrm{P}<0.05$

Table 3. Monthly calculations of the home range of the adult female jackal calculated from $95 \%$, $75 \%$ and $50 \%$ Minimum Convex Polygon Method (MCP) and 95\%, 75\% and 50\% Autocorrelated Kernel Density Estimator Method (AKDE) from 20 November 2018 to 26 June 2019 in Huai Kha Khaeng Wildlife Sanctuary, Thailand

\begin{tabular}{|c|c|c|c|c|c|c|c|}
\hline \multirow{2}{*}{ Month } & \multirow{2}{*}{$\mathbf{N}^{1}$} & \multicolumn{2}{|c|}{ 95\% Home range $\left(\mathrm{km}^{2}\right)$} & \multicolumn{2}{|c|}{$75 \%$ Home range $\left(\mathrm{km}^{2}\right)$} & \multicolumn{2}{|c|}{$50 \%$ Home range $\left(\mathrm{km}^{2}\right)$} \\
\hline & & MCP & AKDE & MCP & AKDE & MCP & AKDE \\
\hline Dec 2018 & 197 & 9.15 & 13.27 & 3.56 & 6.10 & 1.81 & 2.99 \\
\hline Jan 2019 & 228 & 9.89 & 15.10 & 5.73 & 7.61 & 1.89 & 3.82 \\
\hline Feb 2019 & 202 & 10.71 & 23.58 & 6.29 & 12.25 & 4.18 & 6.39 \\
\hline Mar 2019 & 120 & 20.51 & 38.95 & 4.98 & 17.81 & 0.74 & 7.56 \\
\hline Apr 2019 & 226 & 15.52 & 24.17 & 9.85 & 10.08 & 9.00 & 3.35 \\
\hline May 2019 & 144 & 19.85 & 25.87 & 6.40 & 11.51 & 0.86 & 4.58 \\
\hline Pooled data (Nov-Jun 2019) & 1191 & 26.30 & 34.82 & 4.60 & 13.70 & 1.22 & 6.31 \\
\hline
\end{tabular}

Notes: ${ }^{1}$ Number of telemetry locations

The overall home range of the jackal in our study was larger compared to previous studies. Comparing the home range size with the male jackal in HKKWS, monitored with VHF signal by Simchareon (1998) monitored a jackal with a VHF collar for 16 months in HKK, and found the home range to be $9.23 \mathrm{~km}^{2}$ (95\% MCP). In Israel, Rotem et al. (2008) found that home ranges of golden jackals were $21.2 \pm 9.3 \mathrm{~km}^{2}$, which was similar to that found in our study. In general, golden jackals were reported to have home ranges of 1.1-20 $\mathrm{km}^{2}$ (Hunter and Barrett 2011), so our results were consistent with previous findings.
For habitat selection analysis, the $100 \%$ MCP home range size was $61.75 \mathrm{~km}^{2}$, which contained $12.41 \mathrm{~km}^{2}$ of dry dipterocarp (20.1\%) and $49.34 \mathrm{~km}^{2}$ of mixed deciduous forest $(79.9 \%)$. In contrast, there were 668 GPS locations $(56.1 \%)$ in dry dipterocarp forests and 523 GPS locations $(43.9 \%)$ in mixed deciduous forest (chi-squared test = 960.72, $\mathrm{P}<0.01$ ). This result indicates that the female jackal positively selected for dry dipterocarp forest. Our result is similar to that reported by Simchareon (1998), who found that the home range of a male jackal in HKK covered $87.62 \%$ of dry dipterocarp forest in the rainy season and $83.04 \%$ in the dry season. 

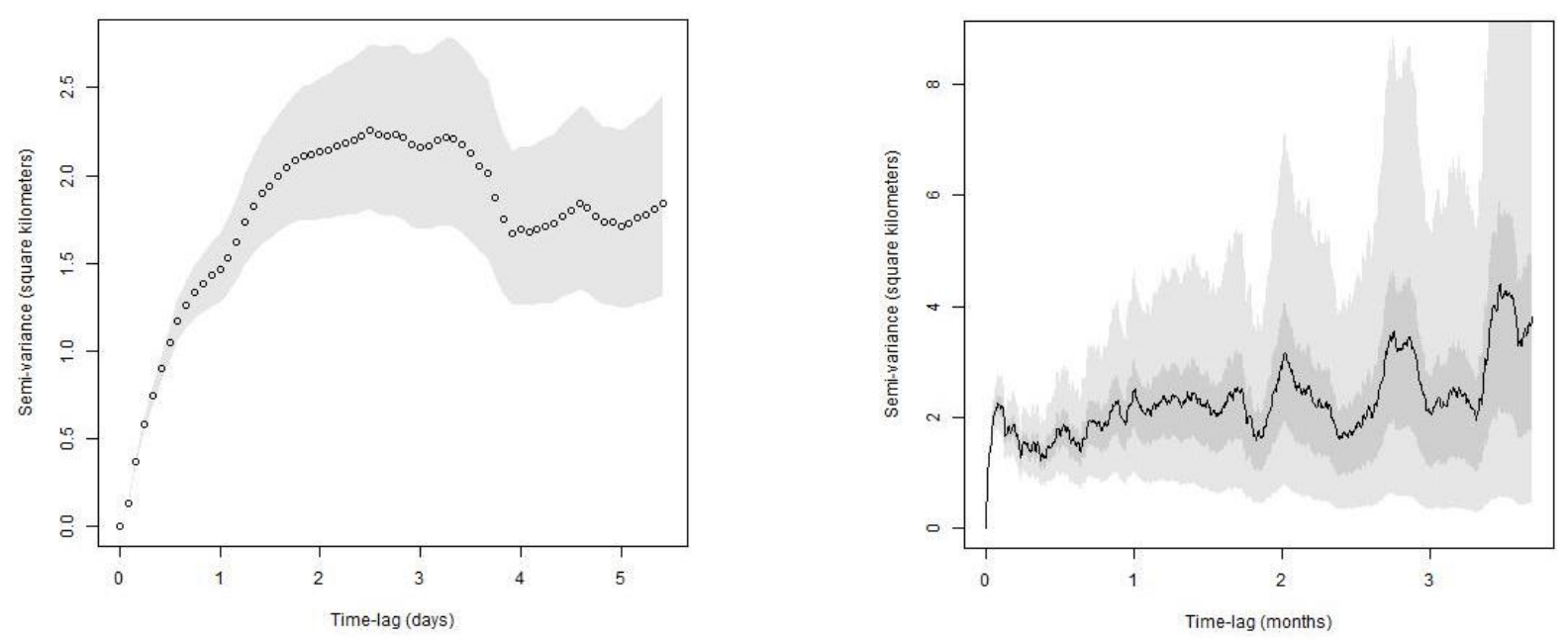

Figure 3. Variogram of the golden jackal between semi-variance and time lag compared between days and months based on AKDE method. Notice that the animal's semi-variance reaches an asymptote within a few days, roughly representing the time to cross its home range and the shading represents the 95\% CL.

Table 4. Species diversity and relative abundance of golden jackal in Huai Kha Khaeng Wildlife Sanctuary around the area between Khao Nang Rum Wildlife Research Station and Huai Kha Khaeng Head Office, Thailand based on camera trap data during November 2017 and October 2018.

\begin{tabular}{|c|c|c|c|c|}
\hline Common name & Scientific name & No. of photos & No. of locations found $(\%)$ & RAI \\
\hline \multicolumn{5}{|l|}{ Carnivorous mammal species } \\
\hline Golden jackal & Canis aureus & 550 & $34(35.8 \%)$ & 24.33 \\
\hline Large Indian Civet & Viverra zibetha & 401 & $63(66.3 \%)$ & 17.74 \\
\hline Leopard & Panthera pardus & 336 & $77(81.1 \%)$ & 14.86 \\
\hline Asian palm civet & Paradoxurus hermaphroditus & 271 & $52(54.7 \%)$ & 11.99 \\
\hline Tiger & Panthera tigris & 119 & $56(58.9 \%)$ & 5.26 \\
\hline Leopard cat & Prionailurus bengalensis & 109 & $37(38.9 \%)$ & 4.82 \\
\hline Dhole & Cuon alpinus & 46 & $28(29.4 \%)$ & 2.03 \\
\hline Small Indian mongoose & Herpestes urva & 43 & $21(22.1 \%)$ & 1.90 \\
\hline Crab-eating macaque & Macaca fascicularis & 32 & $14(14.7 \%)$ & 1.41 \\
\hline Black bear & Ursus thibetanus & 18 & $8(8.4 \%)$ & 0.79 \\
\hline Masked palm civet & Paguma larvata & 12 & $6(6.3 \%)$ & 0.53 \\
\hline Small Indian civet & Viverricula indica & 12 & $9(9.4 \%)$ & 0.53 \\
\hline Large-spotted civet & Viverra megaspila & 7 & $6(6.3 \%)$ & 0.31 \\
\hline Yellow-throated marten & Martes flavigula & 6 & $5(5.2 \%)$ & 0.27 \\
\hline Malayan sun bear & Ursus malayanus & 6 & $5(5.2 \%)$ & 0.27 \\
\hline \multirow[t]{2}{*}{ Hog badger } & Arctonyx collaris & 5 & $4(4.2 \%)$ & 0.22 \\
\hline & Total & 1,973 & Average & 5.45 \\
\hline \multicolumn{5}{|l|}{ Non-carnivorous species } \\
\hline Sambar deer & Rusa unicolor & 1,179 & $85(89.5 \%)$ & 52.16 \\
\hline Red muntjac & Muntiacus muntjak & 478 & $89(93.7 \%)$ & 21.15 \\
\hline Wild boar & Sus scrofa & 407 & $90(94.7 \%)$ & 18.01 \\
\hline Green peafowl & Pavo muticus & 354 & $65(68.42)$ & 15.66 \\
\hline Malayan porcupine & Hystrix brachyuran & 346 & $74(77.89 \%)$ & 15.31 \\
\hline Banteng & Bos javanicus & 333 & $67(70.52 \%)$ & 14.73 \\
\hline Elephant & Elephas maximus & 311 & $84(88.42 \%)$ & 13.76 \\
\hline Red jungle fowl & Gallus gallus & 227 & $38(40.00 \%)$ & 10.04 \\
\hline Siamese hare & Lepus peguensis & 102 & $25(26.32 \%)$ & 4.51 \\
\hline Bengal monitor & Varanus bengalensis & 34 & $19(20.00 \%)$ & 1.5 \\
\hline Rodent & Rodent & 20 & $9(9.47 \%)$ & 0.88 \\
\hline Gaur & Bos gaurus & 18 & $8(8.42 \%)$ & 0.79 \\
\hline Malayan tapir & Tapirus indicus & 12 & $11(11.58 \%)$ & 0.53 \\
\hline Butterfly lizard & Leiolepis reevesii & 12 & $2(2.10 \%)$ & 0.53 \\
\hline Pig-tailed macaque & Macaca nemestrina & 6 & $6(6.32 \%)$ & 0.26 \\
\hline Rhesus macaque & Macaca mulatta & 4 & $3(3.16 \%)$ & 0.18 \\
\hline \multirow[t]{2}{*}{ Hog deer } & Hyelaphus porcinus & 4 & $1(1.05 \%)$ & 0.18 \\
\hline & Total & 3,847 & Average & 10.01 \\
\hline
\end{tabular}


Table 5. The overlap coefficient $(\Delta)$ calculated using Kernel density functions of golden jackal $(\mathrm{n}=550)$ activity sampled via camera trapping between November 2017 and October 2018, in Huai Kha Khaeng Wildlife Sanctuary, (1=identical activity), with approximate $95 \%$ bootstrap confidence intervals

\begin{tabular}{|c|c|c|c|c|}
\hline Common name & Species & $\mathbf{N}$ & $\Delta$ & $95 \%$ bootstrap confidence intervals \\
\hline \multicolumn{5}{|l|}{ Carnivorous mammal } \\
\hline Tiger & Panthera tigris & 119 & 0.86 & $0.88-0.86$ \\
\hline Black bear & Ursus thibetanus & 18 & 0.85 & $0.89-0.85$ \\
\hline Masked palm civet & Paguma larvata & 12 & 0.80 & $0.82-0.79$ \\
\hline Large Indian civet & Viverra zibetha & 401 & 0.78 & $0.78-0.76$ \\
\hline Leopard & Panthera pardus & 336 & 0.78 & $0.78-0.75$ \\
\hline Asian palm civet & Paradoxurus hermaphroditus & 271 & 0.77 & $0.77-0.76$ \\
\hline Leopard cat & Prionailurus bengalensis & 109 & 0.75 & $0.76-0.73$ \\
\hline Small Indian civet & Viverricula indica & 12 & 0.53 & $0.55-0.48$ \\
\hline Dhole & Cuon alpinus & 46 & 0.41 & $0.42-0.38$ \\
\hline \multirow[t]{2}{*}{ Small Indian mongoose } & Herpestes urva & 43 & 0.29 & $0.31-0.28$ \\
\hline & Average & & 0.68 & \\
\hline \multicolumn{5}{|l|}{ Non-carnivorous species } \\
\hline Elephant & Elephas maximus & 311 & 0.88 & $0.88-0.85$ \\
\hline Sambar deer & Rusa unicolor & 1,179 & 0.81 & $0.81-0.81$ \\
\hline Siamese hare & Lepus peguensis & 102 & 0.79 & $0.79-0.77$ \\
\hline Banteng & Bos javanicus & 333 & 0.78 & $0.79-0.78$ \\
\hline Malayan porcupine & Hystrix brachyura & 346 & 0.73 & $0.73-0.70$ \\
\hline Tapir & Tapirus indicus & 12 & 0.65 & $0.65-0.61$ \\
\hline Rodent & Rodent & 20 & 0.61 & $0.63-0.61$ \\
\hline Gaur & Bos gaurus & 18 & 0.52 & $0.54-0.51$ \\
\hline Wild boar & Sus scrofa & 407 & 0.48 & $0.49-0.45$ \\
\hline Red muntjac & Muntiacus muntiak & 478 & 0.43 & $0.44-0.43$ \\
\hline Red jungle & Gallus gallus & 227 & 0.28 & $0.31-0.27$ \\
\hline \multirow{2}{*}{ Green peafowl } & Pavo muticus & 354 & 0.30 & $0.30-0.28$ \\
\hline & Average & & 0.61 & \\
\hline \multicolumn{5}{|l|}{ Ranger activities } \\
\hline Vehicle & - & 5,252 & 0.32 & $0.33-0.32$ \\
\hline Bulldozer & - & 22 & 0.22 & $0.25-0.22$ \\
\hline \multirow[t]{2}{*}{ Human } & - & 494 & 0.26 & $0.27-0.25$ \\
\hline & Average & & 0.27 & \\
\hline
\end{tabular}

\section{Relative abundance index (RAI)}

Camera traps were deployed at 95 locations in Nang Ram Valley, HKK, between November 2017 and October 2018, with a total of 2,260 trap days, and showed 33 species including 16 carnivorous mammal species and 17 non-carnivorous species. Although jackals were recorded in only $36 \%$ of all stations, there were 550 photographs of this species, which resulted in jackals having the highest RAI of any carnivore species (24.33; Table 4). Although leopards were only the third most abundant carnivore species, they were the most widely distributed because they were recorded in $81.1 \%$ of all camera stations. Of all mammal species, jackals had the second-highest RAI, behind only sambar deer (52.17; Table 4$)$, suggesting that jackals are one of the most common mammal species in HKK. Although sambar was the most abundant noncarnivorous mammal, the wild boar was the most widely distributed non-carnivorous mammal because it was recorded in $94.7 \%$ of all camera stations (Table 4).

\section{Activity patterns}

Analysis of jackal activity patterns found that the Mean Vector $(\mu)$ was $00: 46 \mathrm{hrs}$ or at $11.504^{\circ}$ at $95 \%$ Confidence
Interval for $\mu$ between 00: $07\left(1.789^{\circ}\right)-01: 24\left(21.219^{\circ}\right)$ with Circular Variance of 0.662 . Our results were similar to that reported for jackals in Khao Yai National Park (KYNP) (Sukmasuang R 2019, unpublished data), where the $\mu$ was 00: $48 \mathrm{hrs}$ or at $12.192^{\circ}$ at $95 \%$ Confidence Interval for $\mu$ between $00: 12\left(3.005^{\circ}\right)-01: 25\left(21.38^{\circ}\right)$ with Circular Variance of 0.403. For the jackals in Khao Ang Rue Nai Wildlife Sanctuary (KARN) (Ruengtik et al. 2019, pers. comm.) it was found that the $\mu$ was 23: $04 \mathrm{hrs}$ or at $346.111^{\circ}$ at $95 \%$ Confidence Interval for $\mu$ between 19: 35 $\left(293.764^{\circ}\right)-02: 33\left(38.457^{\circ}\right)$ with the Circular Variance of 0.891 . Analytic results of the pooled data from all 3 areas added up to 909 independent photographs, and it was found that the $\mu$ was 00: $04 \mathrm{hrs}$ or at $10.039^{\circ}$ at $95 \%$ Confidence Interval for $\mu$ between 00: $09\left(2.414^{\circ}\right)$ and 01 : $10\left(17.665^{\circ}\right)$ with the Circular Variance of 0.665 . The presence of jackals from camera traps in HKK $(n=550)$ was not significantly different $(\mathrm{U}=0.805)$ from KYNP (Sukmasuang 2019, unpubl. data; $\mathrm{n}=167$ ) and not significantly different ( $U=0.0 .697)$ from KARN (Ruengtik et al. 2019, pers. comm.; $n=192$ ). These results indicate that jackals in HKK have similar activity patterns to those in our protected areas in Thailand. 


\section{Temporal overlap of jackals and other species}

Results from camera traps show that jackals in HKK have temporal overlap activities with other wildlife species in the area. The highest overlap was with Asian elephants, followed by tigers, Asiatic black bears, Sambar deer, masked palm civet, Siamese hare, leopards, banteng, Asian palm civet, leopard cat, Malayan porcupine, tapir, and small rodents. The species that have the potential to be the prey of the jackals in the area that have the highest temporal overlap are the Siamese hare and small rodents with the coefficient of temporal overlap of $0.79(0.79-0.77)$ and $0.61(0.63-0.61)$, respectively. The temporal overlap in the activity of jackals and other wildlife species was consistent with the study results from KARN (Ruengtik et al. 2019, pers. comm.), which found that the jackals had the highest activity temporal overlap with Siamese hare, with similar overlap coefficient value of $0.72(0.72-0.81)$ followed by small rodents with the value of $0.70(0.69$ $0.70)$. The activity overlap coefficient with $95 \%$ confidence intervals of the jackals in HKK and other wildlife species are shown in Table 5.

In conclusion, our results showed that a golden jackal in HKK had a relatively large home range compared to previous studies of golden jackals. Monthly movements appeared to be affected by the seasons, as the smallest monthly movements were in beginning of the dry season and large monthly movement was at the beginning of raining season. Jackals were primarily nocturnal and had relatively high activity overlap with potential prey such as hares and small rodents. Based on the locations obtained from a GPS collar, jackals appear to strongly select for dry deciduous forest compared to mixed deciduous forests. Although their percent occupancy was relatively low, the relative abundance of jackals was higher than all other carnivores, and one of the highest of all mammal species. We conclude that although jackals have relatively large home ranges in HKK, and that their preferred habitat is not common, this generalist species does very well in HKK and is common and abundant member of the mammal community. Future research should investigate their diet and predation impact, and their ecological interactions with other members of the carnivore community.

\section{ACKNOWLEDGEMENTS}

This study was funded by Earthwatch Organization, USA from 2018-2020 and received a scholarship for doctoral-level students from Center for Advanced Studies in Tropical Natural Resources (CASTNaR), Kasetsart University Bangkok, Thailand. The authors would like to thank Dr. Warong Suksavate, Forest Biology Department, Kasetsart University for his help in the data analysis. We would like to thank Thani Wongnak, Head of Huai Kha Khaeng Wildlife Sanctuary. Sompoch Duangchantrasiri, Chief of Khao Nang Ram Wildlife Research Station, Torasak Nipanant, Head of Huai Kha Khaeng Wildlife Sanctuary, Muek Witanyakarn and Huai Kha Khaeng Wildlife Sanctuary staffs, and the Dean of the Faculty of Forestry for their support for this study.

\section{REFERENCES}

Aiyadurai A, Jhala YV. 2006. Foraging and habitat use by golden jackal (Canis aureus) in the Bhal Region, Gujarat, India. J Bombay Nat Hist Soc 103: 5-12.

Azlan MJ, Sharma DSK. 2006. The diversity and activity patterns of wild felids in a secondary forest in Peninsular Malaysia. Oryx 40 (1): 3641.

Azlan MJ. 2009. The use of camera traps in Malaysian rainforests. J Trop Biol Conserv 5: 81-86.

Batschelet E. 1981. Circular Statistics in Biology. Academic Press, London.

Calabrese JM, Fleming CH. 2016. ctmm: an R package for analyzing animal relocation data as a continuous-time stochastic process, Meth Ecol Evol 7 (9): 1124-1132.

Chutipong W, Lynam AJ, Steinmetz R, Savini T, Gale GA. 2014. Sampling mammalian carnivores in western Thailand: Issues of rarity and detectability. Raffles Bull Zool 62: 521-535.

Ćirović D. 2014. Winter diet composition of the golden jackal (Canis aureus L., 1758) in Serbia. Mammalian Biol 79 (2): 132-137.

Ecological Software Solutions. 2019. Biotas. https://www.ecostats.com/Biotas [1 April 2019].

Fernandez-Duran JJ. 2004. Circular distributions based on nonnegative trigonometric sums. Biometrics 60: 499-503.

Forest Research Center. 1997. Application of Remote Sensing and GIS for Monitoring Forest Land Use Change in Huai Kha Khaeng Wildlife

Sanctuary. Faculty of Forestry, Kasetsart University, Thailand. [Thai]

Giannatos G. 2004. Conservation Action Plan for the Golden Jackal Canis aureus L. in Greece. WWF Greece, Athens.

Giannatos G, Karypidou A, Legakisb R, Polymeni. 2010. Golden jackal (Canis aureus L.) diet in Southern Greece. Mammalian Biol 5 (3): 227-232.

Gupta S, Mondal, Sankar K, Qureshi Q. 2009. Estimation of striped hyena Hyaena hyaena population using camera traps in Sariska Tiger Reserve, Rajasthan, India. J Bombay Nat Hist Soc 106 (3): 284-288.

Hoffmann M, Arnold J, Duckworth JW, Jhala Y, Kamler JF, Krofel M. 2018. Canis aureus. The IUCN Red List of Threatened Species. DOI: 10.2305/IUCN.UK.2018-2.RLTS.T118264161A46194820.en. [29 October 2019]

Huter L, Barrett P. 2011. A Field Guide to the Carnivores of the World. New Holland Publishers (UK) Ltd, London, UK.

Jenks KE, Chanteap P, Damrongchainarong, K, Cutter P, Cutter P, Redford T, Lynam, AJ, Howard J, Leimgruber P. 2011. Using relative abundance indices from camera-trapping to test wildlife conservation hypotheses-an example from Khao Yai National Park, Thailand. Trop Conserv Sci 4 (2): 113-131.

Jenks KE, Songsasen N, Leimgruber P. 2012. Camera trap records of dholes in Khao Ang Rue Nai Wildlife Sanctuary. Canid Specialist Group's Canid News. https://www.canids.org/canidnews/15/Camera_trap_records_of_dhole s_in_Thailand.pdf

Jhala, YV, Moehlman P. 2004. Canids: Foxes, Wolves, Jackals and Dogs. In Sillero-Zubiri C, Hoffmann M, Macdonald D (eds.). Status Survey and Conservation Action Plan. IUCN/SSC Canid Specialist Group Gland, Switzerland.

Kingdon J. 1977. East African Mammals: An Atlas of Evolution in Africa-Carnivores. Volume III A. The University of Chicago Press, Chicago.

Kovach Computing Services. 2019. Oriana. https://www.kovcomp.co.uk/oriana/oribroc.html. [1 April 2019]

Lanszki JH, Giannatos G, Heltai M, Legakis A. 2009. Diet composition of golden jackals during cub-rearing season in Mediterranean marshland, in Greece. Mammalian Biol 14 (1): 72-75.

Lanszki JH, Szabó ML. 2006. Feeding Habits and Tropic Niche Overlap Between Sympatric Golden Jackal (Canis aureus) and Red Fox (Vulpes vulpes) in the Pannonian Ecoregion (Hungary). Ecological Research Group, University of Kaposvár, Hungary.

Lekagul B, McNeely JA. 1988. Mammals of Thailand. Damsutha Press, Bangkok, Thailand.

Linkie M, Ridout MS. 2011. Assessing tiger-prey interactions in Sumatran rainforests. J Zoology 284: 224-229.

Lotek Wireless INC. 2019. Terrestrial lite track 330-420. https: //www.lotek.com/products/litetrack-330-420/. [27 October 2019].

Lynam AJ, Jenks KE, Tantipisanuh N, Chutipong W, Ngoprasert D, Gale GA, Steinmetz R, Sukmasuang R, Bhumpakphan N, Grassman LI. 
2013. Terrestrial activity patterns of wild cats from camera-trapping. Raffles Bull Zool 61 (1): 407-415.

Macdonald DW. 1979. The flexible social system of the golden jackal, Canis aureus. Behav Ecol Sociobiol 5 (1): 17-38.

Macdonald DW. 1984. The Encyclopedia of Mammals. Oxford University Press, Oxford.

Mahmood TNF, Nadeem MS. 2013. Diet composition of Asiatic jackal (Canis aureus) in Margallah Hills National Park, Islamabad, Pakistan. J Anim Plant Sci 23 (2): 444-456.

Meredith M, Ridout M. 2018. Overview of the overlap package. https: //cran.r-project.org/web/packages/overlap/vignettes/overlap.pdf [3 May 2019].

Mohr EO. 1947. Table of equivalent populations of North American small mammals. Amer Midland Nat 37: 223-249.

Mukherjee AS, Goyal SP, Johnsingh AJT, Pitman LMRP. 2004. The importance of rodents in the diet of jungle cat (Felis chaus), caracal (Caracal caracal) and golden jackal (Canis aureus) in Sariska Tiger Reserve, Rajasthan, India. J Zool 262 (4): 405-411.

Mukherjee AS, Kumara H N, Bhupathy S. 2018. Golden jackal's underground shelters: natal site selection, seasonal burrowing activity and pup rearing by a cathemeral canid. Mammal Res 63 (3): 325-339.

Network T. 2008. Terrestrial Vertebrate (Camera trap) Monitoring Protocol Implementation Manual. Arlington, VA.

O'Brien TG, Kinnaird MF, Wibisono HT. 2003. Crouching tigers, hidden prey: Sumatran tiger and prey populations in a tropical forest landscape. Anim Conserv 6: 131-139.

Patil, VK, Jhala YV. 2008. Movement pattern and habitat use of golden jackal Canis aureus in Bhal Region of Gujarat. J Bombay Nat Hist Soc 105 (2): 209-243.

Poche RM, Evans SJ, Sultana P, Haque ME, Sterner R, Siddique MA. 1987. Notes on the Golden Jackal (Canis aureus) in Bangladesh. Mammalia 51 (2): 259-270.

Prater SH. 1971. The Book of Indian Animals. Bombay Natural History Society. Oxford University Press, Oxford.

Prayoon, U, Bhumpakphan N, Sukmasuang R, Kanchanasaka B. 2012. Abundance and habitat suitability of Dhole (Cuon alpinus) and their main prey in Thap Lan National Park. J Wildlife Thailand 19: 23-40.

Ridout MS, Linkie M. 2009. Estimating overlap of daily activity patterns from camera trap data. J Agric Biol Environ Stat. 14: 322-337.

Roberts TJ. 1997. The Mammals of Pakistan. Revised edition. Oxford University Press, Karachi, Pakistan.

Rotem G, Berger H, King R, Kutiel PB, Saltz D. 2008. The Effect of Landscape Heterogeneity on Home Range Size and Daily Activity of Golden Jackals (Canis aureus Linnaeus) in Britania Park, Israel. Department of Geography and Environmental Development, BenGurion University of the Negev, Israel.
Šálek MC, Banea J, Krofel OC, Ćirović M, Selanec D, Penezić I, Grill AS, Riegert J. 2014. Population densities and habitat use of the golden jackal (Canis aureus) in farmlands across the Balkan Peninsula. Eur J Wildlife Rese 60 (2): 193-200.

Schaller GB. 1972. The Serengeti Lion. University of Chicago Press, Chicago, IL.

Sheldon JW. 1992. Wild Dogs-The Natural History of the Nondomestic Canidae. Academic Press, Inc., San Diego,CA

Sillero-Zubiri C, Gottelli D, Macdonald DW. 1996. Male philopatry, extra-pack copulations and inbreeding avoidance in the Ethiopian wolf (Canis simensis). Behav Ecol Sociobiol 38 (5): 331-340.

Simchareon S. 1998. Home range of and habitat use by male Asiatic jackal (Canis aureus) at Khao Nang Rum Wildlife Research Center, Thailand. Nat Hist Bull Siam Soc 46: 3-15.

Steiniger S, Andrew JSH. 2013. A User Manual to Perform Home Range Analysis and Estimation with OpenJUMP HoRAE. Department of Geomatics Engineering, University of Calgary, Alberta, Canada.

Siripattaranukul K, Bhumpakphan N, Sukmasuang R. 2015a. Diversity and abundance of carnivorous mammals in Salakphra Wildlife Sanctuary, Kanchanaburi Province. J Wildlife Thailand 22 (1): 127140.

Siripattaranukul K, Paglia S, Sukmasuang R, Horradee S. 2015b. The study of diversity and abundance of wild animal in Chalerm Rattanakosin National Park by camera trapping. J Wildlife Thailand 22 (1): 91-100.

Thai Meteorological Department. 2019. Annual weather summary over Thailand in 2018. http: //www.tmd.go.th/programs/uploads/ yearlySummary/Annual2018.pdf [7 May 2019]

The R Core Team. 2017. The R foundation for statistical computing. https: //www/R-3.4.1/doc/manual/fullrefman.pdf.

White GC, Garrott RA. 1990. Analysis of Wildlife Radio-Tracking Data. Academic Press, San Diego, CA, USA.

Worton BJ, 1989. Kernel methods for estimating the utilization distribution in home-range studies. Ecology 70: 164-168. DOI: $10.2307 / 1938423$

Wongchoo K, Chimchome V, Simcharoen S, Duangchantrasiri S. 2013. Abundance and distribution of some viverrid species in Huai Kha Khaeng Wildlife Sanctuary. Thai J For 32: 1-9.

Yom-Tov, Y, Ashkenazi, S, O, Vine. 1995. Cattle predation by the golden jackal Canis aureus in the Golan Heights. Biol Conserv 31 (1): 19-22.

Yumnam B, T, Negi, JE, Maldonado, RC, Fleischer, YV, Jhala. 2015. Phylogeography of the golden jackal (Canis aureus) in India. PLoS ONE10 (9): e0138497. DOI: 10.1371/journal. pone.0138497.

Zaragozi` B, Belda A, Gimenez P, Navarro JT, Bone A. 2015. Advances in camera-trap data management tools: Towards collaborative development and integration with GIS. Ecol Inform 30: 6-11. 